\title{
2
}

\section{USING VNM EXPECTED UTILITY THEORY TO FACILITATE THE DECISION MAKING IN SOCIAL ETHICS}

\section{Yanick Farmer $^{\mathrm{a}}$}

Abstract: The overall objective of this article is to demonstrate that in applied ethics, certain problems related to decision-making are easier to resolve using conceptual tools borrowed from mathematics than by using philosophical ethics theories, such as classical utilitarianism. With the help of a case study, the first part of the article will attempt to point out that if an agent bases his reasoning on the verbal and purely qualitative concepts of the classical utilitarian theory, he will find himself confronting "undecidable" dilemmas for which making a specific choice rather than another, becomes almost arbitrary. The second part of the article proposes a more formal quantification of utility and attitude towards risk that can help the agent to overcome the uncertainties emanating from a strictly qualitative perception of the real world's configuration, which ends up confusing his practical judgment. This method for decisionmaking is inspired by the works of Howard Raiffa, John von Neumann and Oskar Morgenstern.

Keywords: Social ethics, Decision making, Quantification, Risk, Expected utility.

a Assistant professor of the Department of Social and Public Communication at Université du Québec à Montréal. 
Generally, the reasoning that guides ethical decisions uses two distinctive approaches: it can focus on a certain state of the world produced through action - including the different mental states of the agent -, or it can concentrate itself on the processes, which, if looked at beforehand, can promote "just" or "good" actions. In the first case, the reasoning proceeds by maximization of a predefined magnitude. This is the strategy employed by classical utilitarianism. By first defining goodness - pleasure, well-being or happiness - it then needs to be maximized in terms of costs resulting from the foreseeable consequences of each action. In the second case, the agent's approach is mostly concerned by the introduction of formal constraints which, when applied to reasoning or institutions, favor the achievement of various behaviors considered acceptable from a normative point of view. ${ }^{1}$ This approach is primarily associated with deontological theories like those of Kant and Rawls.

These two modes of reasoning are so common in ethics that they are, to this day, still widely used in various fields that go beyond mere philosophical or ethical thought. However, when it comes to solving somewhat complex practical problems, social ethics is limited by the lack of specification of the conceptual tools it uses. Too often, the mode of reasoning proposed by ethical theory is so broad and imprecise that the agents have no other choice but to leave behind their rational analysis and thus, rely on their intuitive morals - or basically, on their instinct. In practical life, the value of intuition or of sentiment should not be disdained. It must, however, remain peripheral as much as possible, when it comes to addressing problems in which agents must process a considerable volume of information while applying a rigorous analytical method.

The limits of qualitative and purely verbal thought in social ethics appear in at least two recurring dimensions of decision-making: the aggregation of utility and the evaluation of risk. ${ }^{2}$ The first part of the article will attempt to point out that if an agent bases his reasoning on the verbal concepts of the classical utilitarian theory, he will find himself confronting "undecidable" dilemmas for which making a specific choice rather than another, becomes almost arbitrary. The second part will propose an alternative method overcoming the obstacles presented in the first part.

${ }^{1}$ On consequences of this approach concerning questions of justice, see: Sen A., (2009) The Idea of Justice. London: Penguin Books.

${ }^{2}$ Since it is presumed later on in the article that probabilities are assignable to events, the term risk, in this case, is privileged. 
Thus, the overall objective of this paper is as follows: to demonstrate that a slightly more formal quantification of utility and attitude towards risk can help the agent overcome the uncertainties emanating from a strictly qualitative perception of the real world's configuration, which ends up confusing his practical judgment. In what lies ahead, the proposed approach aims to take conceptual tools, which were originally conceived for economics and applied mathematics, and implant them into the field of social ethics. We will now tackle these two aspects of decision-making by attempting, for each of them, to prove that there are indeed alternative forms of quantification. These help the agent specify his choices in contexts where social ethics would usually leave him in a blur of despair.

\section{THE PROBLEM OF AGGREGATION WITHIN CLASSICAL UTILITARIANISM}

The classical utility theory, as developed by Jeremy Bentham and later on by John Stuart Mill, includes three basic components for decisionmaking: a definition of "good" (teleological axis), an imperative (maximization), and other specific principles meant to weigh out preferences. These aspects are derived from a very attractive philosophical anthropology from which the two Anglo-Saxon authors expose what they believe are the most powerful motives of human action.

In this theory, the good, seen as an assessable magnitude, relates to the intensity of pleasure and to the minimization of pain, perceived here as a negative quantity. ${ }^{3}$ To this general finality (telos), is added an imperative (an obligation) which determines the agent's rule of action: to maximize happiness for the greatest number. ${ }^{4}$ Finally, the works of Bentham and Mill will also provide criteria facilitating the balancing of pleasures and the calculation of various utilities. For Bentham, we find a series of seven criteria allowing a quantification of pleasure under an arithmetic form.

3 The problem with the measurability of welfare is already very old in economics. To read about a few classic contributions on this topic see: Robbins L. (1938) Interpersonal Comparisons of Utility; a Comment. In Economic Journal, 43 (December), pp. 635-641; Marshall A. (1949) Principles of Economics 8th ed. (New York: The MacMillan co.); Hicks J.R. (1939) The foundations of Welfare Economics. Economic Journal, 49 (December), pp. 696-700.

${ }^{4}$ See preface: Bentham J. A Fragment on Government, which was brought to attention anonymously in London in 1776. 
The criteria are the following: 1) intensity, 2) duration, 3) certainty, 4) proximity, 5) productiveness, 6) purity, 7) extent. ${ }^{5}$ According to these criteria, an intense pleasure, with a sure and long duration would be preferable to a fleeting, uncertain pleasure, and so forth. While Mill deviates from the quantitative view of Bentham, he also offers a way to calculate different forms of pleasure with a qualitative vision. For example, according to Mill, some intellectual or aesthetic pleasures, even if felt less intensely than sensual pleasures can be more satisfactory. ${ }^{6}$

\section{DECISION MAKING WITH THE HELP OF THE CLASSICAL UTILTTY THEORY}

To this day, the three components of Bentham and Mill's utility theory - but especially the first two - are used to analyze ethical choices in many areas. Clearly, throughout the decades, various critiques were formulated against one or the other of the theory's foundation. The objective here is not to review them all. Among these critiques, many of them focus on the difficulty of evaluating, within a set of options, which one corresponds most accurately to the principle of the greatest happiness for the greatest number. In fact, for the agent who wishes to make a decision by using the utility theory, he is quickly confronted with the uncomfortable assignment of evaluating mental states that are variable in time, but also from one individual to another. ${ }^{7}$ This issue, recognized in philosophy and economics, is known as the aggregation and the interpersonal comparison of utilities. ${ }^{8}$

${ }^{5}$ Bentham. An introduction to the Principles of Morals and Legislation.

${ }^{6}$ See: Mill J.S. Utilitarianism, chapter 2.

${ }^{7}$ Bentham himself recognized this difficulty up until a certain point. See section on this topic in: Arrow K.J. (1963) Social Choice and Individual Values. 2nd ed. New York: John Wiley E` Sons, p. 23 n.

8 The amount of literature on this topic is vast. For an overview in philosophy, economics and applied ethics see, amongst many, the following: Pettit P. (ed.) (1993) Consequentialism. Aldershot: Dartmouth pub.; Parfit D.(1978) Inumerate Ethics. Journal of Philosophy and Public Affairs, 7 (4), pp. 285-301; Taurek J.M. (1977) Should the Numbers Count?. Philosophy $\sigma^{\circ}$ Public Affairs, 6 (4), pp. 293-316; Kahneman D. et al. (1997) Back to Bentham? Explorations of Experienced Utility. The Quaterky Journal of Economics, 112 (2), pp. 375-405; Daniels N. and Sabin J.E. (2002) Setting Limits Fairly. New York: Oxford University Press. 
To demonstrate the limits of the application of classical utilitarianism in applied ethics as well as the advantages of introducing quantification techniques, what follows in this paper is a case study. The case study is fictitious. However, its structure corresponds to what is found in many situations in applied ethics. Thus, its heuristic scope is relatively extended. The case tells the story of a public servant working for the Ministry of Public Security. As part of his duties, he was asked to evaluate the permission to grant the conditional liberation of Nero, a powerful gang lord who, just a few years back, had the whole community terrorized. According to the social psychological expert evaluation that the public servant analyzed, the criminal received sufficient therapy to change the risks of recurrence from "significant" to "moderate". The official knew, however, that upon his arrest 10 years ago, the criminal had sworn to commit significantly damaging crimes when released from prison. Meanwhile, after several budget cuts, the official's superior had demanded the liberation of more prisoners in order to reduce the Ministry's expenses. In light of this, the employee's professional experience as well as his moral intuition, did not encourage him to grant parole. In his opinion, even if the risk had significantly decreased, the consequences of a recurrence would be disastrous. Nevertheless, the employer was a very imperious man and the public servant couldn't help thinking about the precariousness of his non-permanent working status. He was afraid of not being able to feed his family. He was absolutely torn and in need of all the necessary resources to be able to use good ethical reasoning about the issue for he would certainly not want to be wrong. What should he have done: grant Nero's liberation or keep him behind bars?"

Even for an ethical problem with a moderate level of complexity like this one, the shortcomings of the classical utility theory rapidly become apparent. First, the theory does not indicate with much clarity about how to balance personal utility and overall utility of the consequences attached to an action. From the principle of greatest happiness for the greatest number, it is difficult to achieve a fair balance between the intensity factor of the "greatest happiness" and the expansion factor of the "greatest number". Even if the agent does not wish to act in an egotistical manner,

\footnotetext{
${ }^{9}$ The reader is cautioned not to consider the realism of this situation or keep track of the current legislation in criminal law. The reasoning must be based solely on information provided in the example. In any case, once the method is acquired, it is possible to apply it to other contexts with differing information.
} 
the fact remains that according to Bentham's calculating criteria, the certain and the immediate are preferable to the distant and the uncertain. In our example, the sum of the possible dangers affecting the population if Nero were to satisfy his criminal instincts, are considerable. Who would be affected and to what extent? In his case, the public servant also understands very well the consequences involving the relationship between his employer and himself and those concerning the loss of his job. Indeed, these consequences concern but a small amount of people (his family and himself), which does not undermine his perception of their immediacy and certainty.

Furthermore, when the ratio of two effects equally produce intensities of pleasure or displeasure, it is the likelihood of their realization that makes the difference. In other words, at equal intensity, a highly likely consequence will be of greater importance than a consequence of low probability. However, how to calculate probabilities from a sum of purely qualitative judgments? If you put yourself in the employee's place, how do you add up several probabilities that are not quantified? In his reasoning, the employee must calculate the overall utility linked to Nero's liberation, and do the same with the option of keeping Nero behind bars. He would then select the option of the dilemma that overall would be more useful. See, in table 1 below, the type of analysis he can do with the conceptual tools developed by the classical utilitarianism.

The analysis showed in table 1 recaps the most striking aspects of the qualitative analysis of the ethical problem experienced by the public serv-

Table 1

\begin{tabular}{cc}
\hline $\begin{array}{c}\text { OPTION A: NERO'S LIBERATION } \\
\text { Consequences = }\end{array}$ & $\begin{array}{c}\text { OPTION B: LEAVE NERO } \\
\text { IN PRISON } \\
\text { Consequences }=\end{array}$ \\
$\begin{array}{cc}\text { people affected + intensity + probability } \\
\text { peren criminal actions menacing public affected + intensity + probability } \\
\text { security. Indeterminate amount of } \\
\text { people affected. Moderate probability. }\end{array}$ & $\begin{array}{c}\text { Decrease of criminality and menace to } \\
\text { public security. Very high probability. }\end{array}$ \\
\hline $\begin{array}{c}\text { Employer's satisfaction. Job kept and } \\
\text { capacity to nurture family met. Very } \\
\text { high probability. }\end{array}$ & $\begin{array}{c}\text { Conflicts with boss. Job loss. Economic } \\
\text { insecurity risk for the whole family. } \\
\text { Somewhat high probability. }\end{array}$ \\
$\begin{array}{c}\text { Remorse and feeling of deceiving the } \\
\text { ethical and professional integrity re- } \\
\text { quirements. Very high probability. }\end{array}$ & $\begin{array}{c}\text { Feeling of an accomplished duty. Very } \\
\text { high probability. }\end{array}$ \\
\hline
\end{tabular}


ant. The tension arises mainly with the opposition between the employee's personal interest in wanting keep his job and the professional duty inciting him to see the problem with a broader perspective - public protection. When the consequences and their probabilities have been established, how does the calculation go forth? The two options present consequences that are equivalent in their intensity. If Nero is released, the potential significant criminal acts added to remorse give the option a very important negative intensity. The fact that many people can be victims of Nero's actions adds an extension factor to this negative intensity. On the other hand, the possibility of keeping his job, eliminating tensions with the boss and fulfilling the family's needs is a very powerful result that is hard to ignore. This tension between positive and negative consequences also occurs if Nero stays in prison, only in reverse. In short, the mere comparison of the intensity of the consequences appended to the options does not promote a clear, rational choice.

The review of the probabilities expressed qualitatively hardly facilitates the choice. The degree of difficulty would undoubtedly be multiplied were the number of options greater. In option A's column, there are two "fairly high" probabilities and one "moderate" probability whereas in option B's column, we have two probabilities that are "very high" and one that is "fairly high". In terms of probability, there is therefore a slight advantage for option B. However, we must not overlook the average probability associated to a severe consequence - the possibility of Nero's criminal acts touching a large portion of the population. This reasoning, which is based on a qualitative evaluation, brings us to a dead-end. In this case, it would seem that the final decision ultimately rests on the public servant's personality, on subjective intuition made up of an accumulation of temporal experiences which cannot be expressed as a mature and explicitly justifiable choice.

\section{THE PROBLEM WITH UNCERTAINTY AND ATTITUDE TOWARDS RISK}

The difficulty of considering the probabilities of consequences through a qualitative reasoning method is not the only problem with the classical utilitarian approach. If we integrate the notion of the attitude of the agent towards risk to the framework defined earlier, the choice becomes even more complex. Actually, integrating many qualitatively defined probabilities does not suffice. The particular psychological personality coming from 
the type of agent involved also adds itself to the equation. In the end, the ethical choice is made by, on one hand, objective considerations fundamentally linked to the values attributed to the consequences (monetary value, social norms, probabilities, etc), and on the other, by subjective considerations linked to certain dispositions, beliefs and attitudes. Yet, in a selection process which aims to be as accurate as possible, what should we think of an evaluation resulting from the agent's fear, audacity or temerity?

The attitude towards risk is capital because it can substantially modify the agent's calculation of the objective aspects of an uncertain consequence.$^{10}$ For example, it may be that the public servant considers option A of his dilemma (Nero's liberation) as the most favorable because he cannot live with the thought of provoking his boss or losing his income. This result, even if it is unasserted, would give the agent the impression of total loss. Meanwhile, if the public servant has a flare for risk, and since we saw that his professional duty is finely tuned, he could ignore the job loss consequence and choose to follow his good professional judgment which indicates him not to grant the liberation of a dangerous criminal like Nero.

If we go back to table 1, how will the agent integrate the risk factor in the ethical evaluation of the dilemma? Should there be another criteria which would specify the interval of fear or confidence associated to each consequence and its probabilities? In this case, the problems with aggregating qualitative data are accentuated since new margins are being introduced. How do we "average out" the objective aspects of one consequence and the personal beliefs of the agent? Classical utilitarianism does not help us in answering these questions. To avoid this dead-end, the problem's analysis will be resumed by a more mathematical method inspired by John von Neumann and Oskar Morgensterns's work on game theory, as well as Howard Raiffa's work on decision-making. ${ }^{11}$

${ }^{10}$ A criticism of the same nature is elaborated by Harsanyi and directed towards John Rawls's principle of the maximin. See: Harsanyi J.C. (1975) Can the Maximin Principle Serve as a Basis for Morality?. American Political Science Review, 69 (6), pp. 594-606. The works of Harsanyi are by far a significative contribution to the modernization of the utilitarian ethical theory.

${ }^{11}$ Von Neumann J. and Morgenstern O. (2004) Theory of Games and Economic Behaviour. 60th anniversary ed. Princeton: Princeton University Press; Raiffa H., Richardson J. and Metcalfe D. (2007) Negotiation Analysis. The Science and Art of Collaborative Decision-Making. Cambridge: Harvard University Press. 


\section{QUANTIFICATION OF ETHICAL REASONING WITH THE EXPECTED UTILITY MODEL.}

The method exposed in what follows applies itself to a single agent (person, company, government, etc.). Once the problem's options and their respective consequences are defined, the ethical problem's analysis is then quantified. First, the numbered value of each consequence and their likelihood is determined. Second, the desirability of the consequence and the attitude towards risk are evaluated. In this way, the agent takes into account both the "objective" values which he associates to each consequence and the consideration of his own desires and beliefs.

\section{MONETARY VALUE AND PROBABILITY}

The method's first step consists of measuring the consequence's utility by attributing a monetary value to it. Evidently, this exercise is partly subjective since it demonstrates the agent's tastes, but it is also objective in so far as the value of goods often results in recognized social conventions (example: the value of goods and services). If the monetary value is not defined and the agent wishes to transform the qualitative value of a consequence into a quantitative value, he can do so by asking himself this question: how much money would I be willing to spend to have this consequence manifest itself or, on the contrary, be avoided? The agent is including an essential step in what is referred to as the cardinal measuring of utility. ${ }^{12}$ In the exposed case study, for every consequence of option A, the public servant asks himself these questions: 1) What amount of my money would I be willing to pay to avoid newly committed crimes by Nero? ${ }^{13}$ 2) What amount of my money would I be willing to pay to keep my job and to maintain a good relationship with my boss? 3) What amount of my money would I be ready to spend to avoid the

${ }^{12}$ The notion of cardinal utility distinguishes itself from the notion of ordinal utility. Cardinal utility is generally understood as being the intensity of pleasure experienced by the agent at the time of a consequence's realization. As for ordinal utility, it is the result of classification of preferences concerning various consequences managed by the agent.

${ }^{13}$ In this case, the monetary value is accounted as a negative magnitude since it represents a negative consequence for the public servant. All negative consequences will thereby be considered as negative magnitudes. 
Table 2

\begin{tabular}{lclc}
\hline \multicolumn{1}{c}{ OPTION A } & \multicolumn{2}{c}{ OPTION B } \\
\hline \multicolumn{1}{c}{ Monetary Value } & $\begin{array}{c}\text { Probability } \\
\begin{array}{l}\text { Consequence 1A }= \\
-8,000 \$\end{array}\end{array}$ & \multicolumn{1}{c}{$\begin{array}{c}\text { Monetary Value } \\
\text { Consequence 1B }=5,000 \$\end{array}$} & $\begin{array}{c}\text { Probability } \\
0.95\end{array}$ \\
\hline $\begin{array}{l}\text { Consequence 2A = 6,000\$ } \\
\text { Consequence 3A }=\end{array}$ & 0.95 & $\begin{array}{l}\text { Consequence 2B }= \\
-10,000 \$\end{array}$ & 0.8 \\
\hline$-2,000 \$$
\end{tabular}

remorse of having not fulfilled my professional obligations? Once all the monetary values are attributed to the consequences of option $\mathrm{A}$, the agent repeats the procedure for option $\mathrm{B}$. After carefully analyzing the problem, the public servant obtains values which are summarized in the diagram below. Obviously, these evaluations are subjective and can vary considerably from one agent to the next. It is important to note here, that the primary objective is to understand the quantification technique, as such, in so far as it allows the agent to make commensurable choices - the same choices which would have been almost impossible to evaluate from solely qualitative judgments.

Although it is not always the case, in this example, the consequences of each option are almost symmetrical in their form, but not in their values. Thus, as in the qualitative analysis, monetary values alone do not lead to a clear choice. The global utility is quite similar for the two options. For the analysis to progress, the qualitative judgments of the probabilities associated to each consequence must be quantified. All probability finds itself on a 0 to 1 scale in which 0 corresponds to an impossible consequence, and 1 corresponds to a certain consequence. The probabilities of each consequence are portrayed in table 2 . If, for each consequence, we multiply the monetary value by the probability, we obtain the expected monetary value. The sum of the expected monetary values indicates the expected monetary value for each option. ${ }^{14}$

In our example, the calculation gives us these following results:

${ }^{14}$ To see more on these notions, see: Raiffa, Richardson and Metcalfe, op. cit., pp. 23-24. 
- Expected monetary value for option $A=(0.5 \times-8,000 \$)+$ $(0.95 \times 6,000 \$)+(0.9 \times-2,000 \$)=-100 \$$.

- Expected monetary value for option $B=(0.95 \times 5000 \$)+(0.8$ $x-10,000 \$)+(1 \times 2,000 \$)=-1,250 \$$

Contrasting the trend that was previously observed, the integration of the quantified data exposes, for the first time, a clear advantage for option A. However, the suspense of the final decision is yet to come since there are still a few more steps to reach a comprehensive analysis of the problem.

\section{DESIRABILTY, RISK AND EXPECTED UTILTTY}

Already, the quantification of the ethical analysis encourages a better understanding of the problem and shows that options A and B are less symmetrical than what the qualitative assessment suggests. Nevertheless, as it has been previously suggested, it is still possible to go deeper into the analysis by using a model that helps systemize the agent's "interiority" which he expresses through his desires, his attitudes and beliefs. The previous steps focused on the events, while these following steps examine what is happening within the agent as he is confronted by the ethical problem's data.

According to Raiffa, the monetary value that the agent attaches to a consequence is not necessarily proportional to the desire he feels in front of the consequence. This is particularly true when the monetary value is objective and not dependant on the agent's taste. However, the desirability is a fundamental dimension of cardinal utility measuring because it indicates the intensity of the agent's preferences. ${ }^{15}$ For example, if it is obvious that the monetary value of a Ferrari 458 Italia is much higher than that of a Toyota Prius, it is possible to perceive the agent's desirability for the second choice as being stronger - that is, if he has an ecological tendency or dislikes bling. Yet, there is more. Desirability also measures the real impact of a good or of a consequence affecting the agent. For most people,

${ }^{15} \mathrm{On}$ this topic, there is no consensus on the employed terminology. For more precisions, see amongst others: Fisher I. (1918) Is Utility the Most Suitable Term for the Concept It is Used to Denote?. American Economic Review, 8, pp. 335-337; Fishburn P.C. (1989) Retrospective on the Utility Theory of von Neumann and Morgenstern. Journal of Risk and Uncertainty, 2, pp. 127-158. 
winning one million dollars is extraordinary; for Bill Gates, it is pretty banal. Consequently, it is sometimes preferable, says Raiffa, to add a desirability factor to the calculation of the monetary value. ${ }^{16}$ Desirability is represented by a number between 0 and $100-100$ being the highest degree of desirability and 0 , the lowest. In the example of the public servant, the monetary values are the direct expression of the agent's desires. Desirability is therefore proportionate to monetary values and so we can exclude it from our calculations as it will not contribute any extra information. ${ }^{17}$

Once the agent has identified his preferences and their intensity by attributing a monetary value to them, he must go through another step to conclude the utilitarian reasoning. Even if two agents can agree on the consequences which, in their view, are most desirable, it is far from certain that they will agree on what they are willing to risk to see the consequences manifest themselves. The variable of this decision lies in the attitude towards risk. We have seen that in a qualitative type of reasoning, the risk factor seriously affects the complexity of the ethical problem's analysis. Hence the question: how can we integrate it to the rest of the quantification of the decision-making process?

Again, numerous authors have dwelled on the question of modeling decisions in risk contexts. However, following Raiffa, ${ }^{18}$ the ethical analysis method elaborated in the later part of this essay will reflect John von Neumann and Oskar Morgenstern's ideas proposed in Theory of Games and Economic Behavior. Thus, when the utility of a consequence depends not only on its intrinsic value or desirability, but also on the risk factor (odds and beliefs) that is appended to it, the agent's choice will take the form of a lottery. Indeed, like all uncertain consequences, the lottery produces a certain gain factor $-\mathrm{X}$, with a probability $-\mathrm{p}$. For example, if the rule of the lottery specifies that I will obtain $10 \$$ if, by rolling a die, I get a six, this means that $\mathrm{X}$ is equal to $10 \$$ and therefore $\mathrm{p}$ is equivalent to $1 / 6$. This data will help characterize the lottery and calculate its utility. According to Neumann and Morgenstern, when faced with the core of this situation, the agent - if he is rational - will search a way to maximize the expected utility. Consequently, between two lotteries, he will choose the

${ }^{16}$ Raiffa et al., op. cit., pp. 24-26.

${ }^{17}$ If we apply the desirability notion to the example of the public servant, the results would be the following: the consequence $2 \mathrm{~A}$ would have the highest degree of desirability (100) and the consequence $2 \mathrm{~B}$ would have the lowest degree of desirability (0).

${ }^{18}$ Raiffa et al., op. cit., pp. 27-32. 
one whose expected gain is the highest. In the context of ethical decision, the concept of lottery is therefore used to model choice within a risk context. Altogether, it is an analogy of realistic bets which an agent must sometimes make when he finds himself in front of an uncertain future. ${ }^{19}$

Through the acceptance of certain postulates or axioms ${ }^{20}$ that reflect the consistency of the agent, it becomes possible to reformulate the data of the ethical problem in the form of lotteries. The utility calculated by this method is called expected utility or von Neumann-Morgenstern's utility (vNM). The first consistency or rationality postulates are considered natural. ${ }^{21}$ They may be conformed to the rules of logic usually employed by an agent when he reasons with different choices. In fact, these assumptions provide the agent with the stability and reproducibility of his preferences. In this way it is possible to make "understandable" choices, which is to say, choices that are rationally justifiable and predictable. These postulates are also necessary for the establishment of formal preference profiles referred to here as utility function.

The first of these postulates requires the formulation of preferences in the form of a complete pre-order. ${ }^{22}$ This concept states that within a set of consequences, the agent can compare all ${ }^{23}$ consequences by pairing them up two by two. He can then establish that, if he prefers consequence

${ }^{19}$ In economics literature, many authors believe that von Neumann and Morgenstern's notion of expected utility does not describe realistically the agent's behavior in risk contexts. For example, this was the case for the French economist, Maurice Allais. This essay does not strive to take position on the matter, but rather suggests the calculation of utility according to vNM is a practical conceptual tool for decision making in applied ethics.

${ }_{20}$ These postulates have been criticized by numerous authors. Since this article does not make its case on their critical examination, the reader can consult the vast literature dedicated to this subject. See: Fishburn P.C. (1970) Utility Theory for Decision Making. New York: Wiley; Machina M.J. (1982) Expected Utility : Analysis without the Independance Axiom. Econometric, 50 (2), pp. 277-323; and more recently Risse M. (2002) Harsanyi's 'Utilitarian Theorem' and Utilitarianism. Noûs, 36 (4), pp. 550-577.

${ }^{21}$ It should be noted that the following presentation is an informal interpretation of the formal demonstration conceptually originating from von Neumann and Morgenstern.

${ }^{22}$ On this topic, see: Harsanyi J.C. (1978) Bayesian Decision Theory and Utilitarian Ethics. American Economic Review, 68 (2), pp. 223-228.

${ }^{23}$ For some authors, including Amartya Sen, this requirement is too strong and is not necessary to ensure the consistency of choice. For details, see: Sen A. (2001) Rationality and Freedom. Harvard: Harvard Belknap Press. 
$\mathrm{x}$ to consequence $\mathrm{y}$, and $\mathrm{y}$ to $\mathrm{z}$, he therefore prefers $\mathrm{x}$ to $\mathrm{z} \cdot{ }^{24}$ The second assumption is very important for modeling. Under this assumption, if lottery Q ranks, in terms of preferences, between two other lotteries let's say $\mathrm{P}$ and $\mathrm{R}$, it is thus possible to reconstruct lottery $\mathrm{Q}$ as a lottery formed by $\mathrm{P}$ and $\mathrm{R}$ while keeping its preference order. This is a continuity postulate. The third postulate is also essential for what follows. It is a substitution ${ }^{25}$ postulate. This postulate provides two forms of equivalence. ${ }^{26}$ On one hand, whether they are composite or single, ${ }^{27}$ the utility of the two lotteries which have equal expectations of gain will be deemed equally preferable by an agent. ${ }^{28}$ The physical process that produces a result is not important. What counts, is the result itself. On the other hand, at the end of a calculation method which we will now explain, the probability of a lottery is the direct expression of its utility. ${ }^{29}$

The technique von Neumann and Morgenstern propose is clever and very useful in applied ethics. For the modeling of the ethical problem to simultaneously reflect the probabilities, the desirability and the attitude towards risk, the agent must transform the consequentialist qualitative analysis into a lottery characterized by a certain gain expectancy. From a psychological standpoint, we find in this mathematical procedure the idea that the decision in front of risk is pulled from one extreme to the other: the temptation to make a significant gain or the deception of an important loss. The risk-seeking agent will be more attentive to the lottery's promise of gain, whereas the risk-averse agent, will be more preoccupied by the potential losses. To create a lottery, the best consequence of the considered option must be first identified, followed by the identification of the worst. We must then link these consequences to their

${ }^{24}$ The order is qualified here as transitive. This axiom also presupposes the comparability of the options.

${ }^{25}$ In various writings, this postulate is also described as an independence axiom.

26 This explanation is borrowed from Binmore's work. See: Binmore K. (1992) Fun and Games: A Text on Game Theory. London: DC Heath.

${ }^{27}$ A composed lottery is one in which the prizes are themselves the lottery. According to the substitution postulate, a composed lottery can be brought back to a simple lottery by calculating the total probability. See Binmore, op. cit.

${ }^{28}$ Evidently, this excludes any case in which the "player" is not primarily motivated by the results, but rather by the mere pleasure of playing. After all, if the fun of the game were not sometimes stronger than the systemic research of results, Las Vegas would be bankrupted!

${ }^{29}$ Binmore offers an excellent summary of von Neumann and Morgenstern's demonstration. See Binmore, op. cit. 
monetary value thus exposing either the benefits (gains) promised by the lottery, or the losses. This lottery is graded Q; the superior prize (the "gain") is graded G and the inferior prize is graded L. Each lottery is defined by the set $[G, L]$. Next, the agent must identify - within the interval $[\mathrm{G}, \mathrm{L}]{ }^{30}$ the amount which, to him, seems to be an "average desirability". That is to say a desirability of 50 on an interval $[0,100] .{ }^{31}$ This amount is very significant as it helps measure, specifically, the agent's attitude towards risk. We will see why later in the presentation.

Now, putting ourselves in the public servant's shoes, we must compare the options to construct the lottery and ask ourselves these following questions: what is the best outcome I can achieve from choosing one or another option? And which is the worst? For the model to adequately reflect the ethical choice, it is important to grasp the tension between the temptation for gain and the great loss that would result if the worst consequence were to occur. By establishing beforehand the monetary value and the desirability, we've already gone through this exercise. In option $\mathrm{A}$, the best consequence for the public servant is keeping his job (2A), and the worst one is Nero's recidivism (1A). The sum of the lots would therefore be $\{6000,-8000\}$. This lottery structure indicates that should he choose option $\mathrm{A}$, the public servant would want, above all, to keep his job, but he would have to accept the risk of Nero's recidivism. Inversely, should he choose option $\mathrm{B}$, the public servant opts for the idea of avoiding public security threats (1B) while risking his job (2B). For option $B$, the sum of the lots would therefore be $\{5000,-10000\}$. The final choice will result in the comparison of option $A$ and B's lotteries. ${ }^{32}$ In the interval $\{6000,-8000\}$, we will assume that the average desirability grade is $-1000 \$$. This amount signifies that the public servant feels indifferent about choosing either option whether it be that of paying $1000 \$$ from his pocket or that of participating in a lottery. In the interval $\{5000,-10000\}$, the desirability's average is set at $-2500 \$$.

To determine the probability - and therefore the utility ${ }^{33}$ - associated to each lottery deriving from the consequences, the agent must first ask

${ }^{30}$ Contrarily to the group that contains only elements $G$ and L, the interval includes all values between $G$ and $L$.

${ }^{31}$ See footnote 16 for further explanation.

${ }^{32}$ This model choice seems closer to a common type of reasoning. In real life, the agent would compare the risks and gains of each option and do likewise for the two lotteries.

33 This results from the substitution postulate that was defined earlier. 
himself this question: what would have to be the probability attributed to lottery Q's gain to incite me to change $\mathrm{X}$ amount of my consequence in exchange for a ticket allowing me to participate in the lottery? Normally, if the agent is risk-neutral, the average desirability scale will correspond to a 0,5 probability. This means that he would be indifferent to choosing between the option of paying $1000 \$$ (or $2500 \$$ for option B) and the option of participating in the lottery. However, if the agent is timorous, he would even be willing to pay a substantial amount to avoid the risk of loosing prize L of the lottery. After, the agent must repeat the process and ask himself that same question for each of the dilemma's consequence. The ingenuity of the procedure comes from the fact that by asking this question, the agent not only compares utilities and probabilities. He also assesses how far he is willing to go to see the realization of the consequence for which he cares most. The obtained probability for each consequence becomes a way to measure the lottery's utility while taking into account the attitude towards risk. It is then multiplied by the probability, in table 2 , to which the consequence's realization is attributed. ${ }^{34}$ The multiplication's result is the consequence's expected utility. The sum of the expected utilities for each option's consequence gives us the total of the expected utility of an option.

Here are the results of the consequences transformed into lotteries. The reader can refer to the tables 1 and 2 for further details. Note that in table 3 , the number associated to the consequence is the probability determined by the agent in a range between 0 and 100 .

As was reported earlier, to calculate the expected utilities of each result, the utility noted in table 3 must be multiplied by the consequence's probability and each option's results are to be added. This is the calculation in brackets in table 3. We now have all the necessary data to go ahead with the two option's comparison within a utilitarian perspective. In light of these results, we can observe that, with an ethical point of view, the most desirable option for the state employee is option B - not granting Nero's liberation. The method makes it possible to aggregate all of the problem's data and end up with a clear choice, which was not the case with a purely qualitative analysis. This can easily be experienced: the qualitative

\footnotetext{
${ }^{34} \mathrm{It}$ is important to understand here the difference between each probability. The one from table 2 is an "objective" evaluation of the possibility of seeing the outcome of a consequence while the other integrates a measurement of the agent's desire in a risk context.
} 
Table 3

OPTION A

OPTION B

\begin{tabular}{ll} 
Consequence $1 \mathrm{~A}=0.01(\mathrm{x} 0.5=0.01)$ & Consequence $1 \mathrm{~B}=1(\mathrm{x} 0.95=0.95)$ \\
\hline Consequence $2 \mathrm{~A}=1(\mathrm{x} 0.95=0.95)$ & Consequence $2 \mathrm{~B}=0.01(\mathrm{x} 0.8=0.01)$ \\
\hline Consequence $3 \mathrm{~A}=0.4(\mathrm{x} 0.9=0.36)$ & Consequence $3 \mathrm{~B}=0.8(\mathrm{x} 1=0.8)$ \\
A's total utility $=1.32$ & $\mathrm{~B}$ 's total utility $=1.76$ \\
\hline
\end{tabular}

judgment becomes hazy when a large amount of information is to be considered. The quantification of the problem promotes, instead, a more accurate model that encourages the agent to distance himself from the ambivalence generated by a fixation on the qualitative data of his dilemma.

\section{THE DEONTOLOGICAL CONSTRAINTS WHICH ASSURE THE CHOICE'S ETHICALTYY}

Obviously, for some critics of utilitarianism, the " ethicality " of such a decision is never guaranteed as it is based on determinants, such as desirability, which may be contaminated by personal interest. The addition of what might be called deontological "constraints" could create a procedural "lock" of some sort which would secure the decision-making process. This issue alone would require another article. Harsanyi and other authors, have suggested solutions to this problem. ${ }^{35}$ If we refer to Kantian's ideal, the essence of deontological ethics obliges the agent to a certain form of universality through which the agent's actions must obey to principles of symmetry between agents, impartiality towards his own interests, and exemplarity. The integration of these constraints to the model proposed in this paper is not an easy task. Through his notion of the categorical imperative, Kant placed more emphasis on the formal properties of practical reasoning. However, it is difficult to make choices and respect these properties without considering the consequences that these choices produce. The introduction of ethical constraints would probably require a closer look at the issue of distribution of utilities, since this question reflects the moral status of agents in a community. This issue therefore calls for the definition of principles of justice. Clearly, this goes beyond the scope

\footnotetext{
${ }^{35}$ See Harsanyi, op. cit., p. 226-228.
} 
of this article, but it would be enticing to delve deeper to make the method of decision-making more beneficial to public officials.

\section{CONCLUSION}

Ethics, like other realities, is grasped through the complex overlapping and intermingling of magnitudes, intensities, movements, spaces and forms. Ethicists would therefore gain from the advantage in precision and generativity which are almost infinite in the mathematical language. It should be remembered that philosophy as a discipline is not experimental, but rather analytical. Like mathematics, it contributes to knowledge by using reasoning and new logical sequences likely to renew our perception of the world. Unfortunately, practitioners of ethics usually choose to limit their analytical methods to the categories and modes of designating specific to natural language. ${ }^{36}$ They then lock themselves up in very general principles that too often lead to ineffective verbiage. This is because the syntax of natural languages is very old and mostly related to spatial and temporal phenomena reflecting everyday life. This limits its modeling and analytical power. In social ethics, issues concerning the aggregation of utility and risk assessment are eloquently demonstrated. As dramatically portrayed in the history of physics, natural language is primarily a means of communication. Nevertheless, nowadays, social ethics is slow to integrate the mathematical tool in its basic training. It emphasizes History and condemns those who practice it as being mere commentators who endlessly repeat the words of the past. If ethics practitioners want to change the world instead of remaining passive describers of it, they will have to discover new grounds which have already been broken by Archimedes' descendants.

\footnotetext{
${ }^{36}$ For other considerations on the relation between mathematics, ethics and limitations of natural languages, see: Farmer Y. (2010) Topologie and modélisation chez René Thom: l'exemple d'un conflit de valeurs en éthique. Philosophiques, 37 (2), pp. 369-386.
} 